\title{
Prior residency improves the performance of a habitat specialist in a degrading environment
}

\author{
Davina E. Poulos ${ }^{1,2} \cdot$ Mark I. McCormick ${ }^{2,3}$
}

Received: 11 August 2021/Accepted: 22 January 2022/Published online: 13 February 2022

(C) The Author(s) 2022

\begin{abstract}
The effect of habitat loss on the decline of habitat specialists has been well documented in coral reef fishes, since they have a restricted habitat preference. However, the different competitive advantages of specialists and generalists can impact their performance within varying habitat conditions. The order in which species arrive into a community influences competitive outcomes; these 'priority effects' may modify communities within degrading resource scenarios as individuals migrate in search of higher quality resources. In this study, we investigated: how sequence and timing of arrival affects interactions between a habitat generalist and a specialist in healthy and degrading environments, and how prior residency interacts with habitat quality and species identity to affect propensity to migrate. We conducted manipulative field studies using the damselfishes Pomacentrus amboinensis, a habitat generalist, and Pomacentrus moluccensis, a live coral specialist, on live or dead coral habitats, with timing of arrival differing between early and late arrivers (residents and intruders, respectively) by 1,3 or $24 \mathrm{~h}$. Our results demonstrated that the strength of priority effects (i.e., aggression intensity) increased with increasing timing of arrival when the $P$. moluccensis
\end{abstract}

Topic Editor Alastair Harborne

Mark I. McCormick

markianmccormick@gmail.com

1 College of Marine and Environmental Sciences, James Cook University, Townsville, QLD 4811, Australia

2 ARC Centre of Excellence for Coral Reef Studies, James Cook University, Townsville, QLD 4811, Australia

3 Present Address: School of Science, Coastal Marine Field Station, University of Waikato, Tauranga, New Zealand arrived after $P$. amboinensis, suggesting that as the perceived value of the habitat patch increased (owing to increasing ownership duration and defence investment), the tendency to defend it increased. Propensity to migrate from dead to live coral was greater for $P$. moluccensis compared to $P$. amboinensis; however, arriving after $P$. amboinensis significantly reduced willingness to migrate to its preferred live coral habitat, indicating an inhibitory priority effect, directly affecting future persistence. The degree that ecological versatility and priority effects combine to modify competitive outcomes in coral reef fishes has important consequences for the persistence of specialist species in the face of environmental degradation, and has implications for predicting how our changing environment will affect fish communities.

Keywords Aggression - Competition - Habitat quality · Migration · Priority effect · Habitat specialisation

\section{Introduction}

Environmental and anthropogenic-induced changes are causing increased stress to natural systems, resulting in a decline, and in extreme events a loss, of species worldwide (Ceballos et al. 2017; Sanchez-Bayo and Wyckhuys 2019; Smale et al. 2019; Kleypas et al. 2021). This loss of biodiversity has emphasised the importance of determining which species are most at risk, the factors directly influencing the decline in abundance of vulnerable species, and how their decline alters the dynamics of communities (Feary et al. 2014; Madin et al. 2016; McKenzie et al. 2016; Gladstone-Gallagher et al. 2019). The survival and future persistence of species within a changing environment are reliant on successful acclimation or adaptation to 
new, and often degrading, resources (Huey et al. 2012). Ecological versatility, 'the degree to which organisms can fully exploit the available resources in their local environment'(MacNally 1995), is one mechanism that explains how species will perform under changing resource scenarios (Colles et al. 2009). How specialised an organism is in its dependency on key resources may determine the likelihood of its extinction in the face of resource decline (Clavel et al. 2011). Species with a high level of habitat specialisation (specialists) are restricted to a small number of preferred habitats, whilst species that are versatile in their habitat use (generalists) use a range of different habitat types within their local environment (Feary 2007; Berkström et al. 2012).

As marine habitats continue to degrade and decline (Stuart-Smith et al. 2018), so too will the organisms that rely on these for food and shelter (Pihl et al. 2006). In coral reef ecosystems, the loss of coral following bleaching events, crown of thorns starfish outbreaks, cyclones (De'ath et al. 2012; Cheal et al. 2017), pollution (Fabricius 2005), and many other impacts, has flow-on effects to the associated fish communities (Jones et al. 2004). Several studies have documented the decline of habitat specialist fish species as a result of coral loss (Graham 2007; Wilson et al. 2008; Pratchett et al. 2012), but few studies have concurrently examined other factors that may modify this process. As individuals seek higher quality habitats, the structure of assemblages will be disrupted and altered, but the different competitive advantages of generalists and specialists in particular habitats will influence who persists (Morris 1996). Alternate or adaptive behaviours that reduce conflict can result in multiple social niches thereby increasing an individual's fitness. These niches stem from differences in resource distribution, social hierarchy structure and spatial or temporal variation in resource use, allowing varied behavioural responses and thus promoting cooperation (Bergmüller and Taborsky 2010).

Temporal differences in the use of habitats between competitors may alter interspecific competition by either facilitating or inhibiting coexistence (Lawler and Morin 1993; Rollins and Benard 2020). The sequence and timing in arrival of species into a community can have a profound effect on competition and subsequent community structure (Hodge et al. 1996); however, few studies have examined how the strength of these 'priority effects' are affected in degrading resource scenarios, particularly in the marine environment. Of these, there is conflicting evidence about how habitat quality or complexity affects competition between prior residents and new arrivers in coral reef fishes, by either having no effect (Geange and Stier 2010) or by ameliorating its effects (Adam 2011). Terrestrial studies have demonstrated that the magnitude of priority effects depends on resource condition and/or availability
(Kardol et al. 2013; Tucker and Fukami 2014), and that priority effects strengthen as timing of arrival for late-arriving species increases following environmental disturbance events (Symons and Arnott 2014). For instance, Rudolf and McCrory (2018) experimentally manipulated the relative arrival time of two competing tadpole species across a food availability gradient and found that delaying the relative arrival of a species to a pond reduced the interaction asymmetry between species and could reverse competitive dominance. Prior residents gain several advantages from arriving early (such as knowledge of the habitat layout and assemblage), but most importantly they may gain competitive dominance over late-arriving individuals if no other significant asymmetries exist (such as body size), which can override priority effects (Evans and Shehadi-Moacdieh 1988; Beaugrand et al. 1996; Poulos and McCormick 2014). Therefore, it becomes important to understand how priority effects relate to other deterministic factors in structuring local communities, so that predictions about future community dynamics are accurate in the face of environmental change.

Our study used an ambitious series of field experiments to investigate the role of priority effects and ecological versatility in coral reef fish community dynamics, within a degrading environment. As a foundation for future studies, we compared how two species with different levels of habitat specialisation interacted in healthy and degraded coral habitats with respect to sequence and timing of arrival, and evaluated what their behaviour and propensity to migrate told us about the modified structure of fish communities within the altered environment. It was predicted that the habitat specialist (the species that preferred live coral habitats) would perform poorly in degraded habitats, but it was unknown whether (and how) priority effects could modify this outcome. Specifically, we tested the following: (1) how does the sequence (i.e., order of arrival) and timing of arrival (i.e., duration of priority) affect interactions between the two fish species in healthy and degrading habitats? (2) how does prior residency interact with habitat quality to affect propensity for the two fish species to migrate; and (3) how does habitat quality, prior residency, and migration affect survival?

\section{Materials and methods}

\section{Study system, species and site}

Coral reefs are degrading worldwide (Hughes et al. 2017), and degradation occurs in ways that are often spatially patchy at local, within-site scales due to agents of change that include coral thermal or freshwater bleaching and crown of thorns starfish feeding (De'ath et al. 2012). Fish 
communities are replenished by the input of new individuals that metamorphose, settle and join the reef population at the end of a larval phase that averages 2 to 3 weeks in duration (Leis and McCormick 2002). This flood of new juvenile individuals comes onto a reef in lunar pulses with peaks that vaguely coincide with the new moon for damselfish (Dixon et al. 1999). These pulses of juveniles may extend for 2 weeks per month, during which inputs can fluctuate markedly in magnitude between consecutive days. Most settlement appears to occur overnight in coral reef fishes (Dufour and Galzin 1993; Schmitt and Holbrook 1999), but it is currently unknown the extent to which behavioural dynamics that occur at night affect subsequent dynamics. Schmitt and Holbrook (1999) studied the settlement dynamics of humbug damselfishes over 14d using infra-red video and managed to get information on 25 recruits. All recruits were found to remain on the microhabitats to which they had settled and all survived until daylight. This suggests that although interactions may have established hierarchies in the dark, the results of those interactions (i.e., social hierarchy) would be evident in daylight hours. While the current study manipulated settlement dynamics during daylight hours, it is likely that the behavioural processes are similar to those of naturally settled fish, though further studies are warranted to test this assumption.

While it is typical for most juveniles to be strongly site attached during the initial few days or months after settlement, there is some immediate renegotiation of space through migration (Lewis 1997), and some species also undergo a series of habitat and species associations before having a longer term association with a particular home range (McCormick and Makey 1997). For damselfish, one of the most speciose families of tropical fishes, it is typical for fish to settle to an area that will form the core of their life-long home range. While many display strong preference for habitat at settlement (Öhman et al. 1998; Coker et al. 2014), these preferences are often modified by the presence of other species already resident on the habitat patch. For example, research has shown that the selection of a settlement habitat patch can be influenced by the presence of resident predators (Vail and McCormick 2011), the presence of adults of similar or different species (Öhman et al. 1998), and the presence of other juvenile fishes (Sweatman 1985, 1988). Research suggests that late larval-stage fishes settle to the reef mostly at night (Dufour and Galzin 1993) and that events that occur within the first few days after settlement have a dramatic influence on subsequent behaviour (Poulos and McCormick 2014; Ferrari et al. 2015), growth trajectories (Gagliano and McCormick 2007; Gagliano et al. 2007; Goldstein and Sponaugle 2020), abundance patterns of later life stages
(Williams et al. 1994; Booth et al. 2000; McCormick 2012) and fitness (McCormick et al. 2010b).

Juvenile damselfishes, Pomacentrus amboinensis and $P$. moluccensis, were used in this study. The Ambon damselfish, $P$. amboinensis, is a habitat generalist, equally selecting live or dead coral habitats at the time of settlement (Öhman et al. 1998), but can also show a greater preference for live coral (McCormick et al. 2010a; Pratchett et al. 2012) on which it exhibits a slightly lower mortality rate (McCormick 2012). The lemon damselfish, $P$. moluccensis, is a habitat specialist, preferentially selecting live coral habitats (Öhman et al. 1998; McCormick et al. 2010a), and showing significantly greater mortality on dead coral than live coral habitats (McCormick 2012). Both species coexist as juveniles, have similar morphologies, but differ slightly in their habitat use and behaviour (McCormick and Weaver 2012). It is unclear what $P$. moluccensis obtains from the live coral other than shelter, but when $P$. moluccensis are caged on thermally bleached coral their body condition slowly declines (McCormick et al. 2010a). In the present study, these species were caught in light traps (Meekan et al. 2001) deployed overnight off Lizard Island (northern Great Barrier Reef, Australia) and carefully transported to the laboratory immediately upon collection at dawn where they were placed in $25 \mathrm{~L}$ flow-through aquarium tanks without habitat. Individuals caught in light traps are near the end of their larval phase, and having not yet settled on the reef they are naive to reef-based dynamics.

Small patch reefs (approximately $0.3 \mathrm{~m}^{3}$ ) of the hard bushy coral Pocillopora damicornis were constructed in a grid of two lines of 10 reefs $3-4 \mathrm{~m}$ apart on bare sand, $50 \mathrm{~m}$ from the nearest reef edge, at the shallow backreef of Lizard Island. Treatments were alternated on reefs. Half the patch reefs consisted of $100 \%$ live coral and the other half of $100 \%$ dead-degraded algal-covered coral (e.g., see Fig. 1 in McCormick and Lönnstedt 2016). Both patch types had similar structural complexity. Fishes were transported to the field site after being held in the laboratory for at least $24 \mathrm{~h}$ and up to $48 \mathrm{~h}$ (to recover from the stress of capture) and then placed on patch reefs according to the following experimental procedures.

\section{Experiment 1: competition}

The four factors manipulated in a large field experiment were: (a) species ( $P$. amboinensis and P. moluccensis), (b) sequence of arrival (early or late-arrival), (c) timing of arrival (i.e., the temporal period between the arrival of the early and late individuals at the patch reef; $1 \mathrm{~h}, 3 \mathrm{~h}$ or $24 \mathrm{~h}$ priority periods), (d) habitat quality (live or dead coral patch reefs), with 10 to 22 replicates (mean 17) of each scenario (see Fig. 2 legend for $n$ ). Thus, at each level of 
Fig. 1 Mean number of chases per minute $( \pm$ SE) on live and dead coral with timing of latearrivers being 1,3 or $24 \mathrm{~h}$, when a Pomacentrus moluccensis (white bars) arrives early and Pomacentrus amboinensis (grey bars) arrives late, and $\mathbf{b}$ when Pomacentrus amboinensis (white bars) arrives early and Pomacentrus moluccensis (grey bars) arrives late. Letters above bars represent Tukey's HSD groupings. Photographic credits M. McCormick. $N=10-22$ per scenario

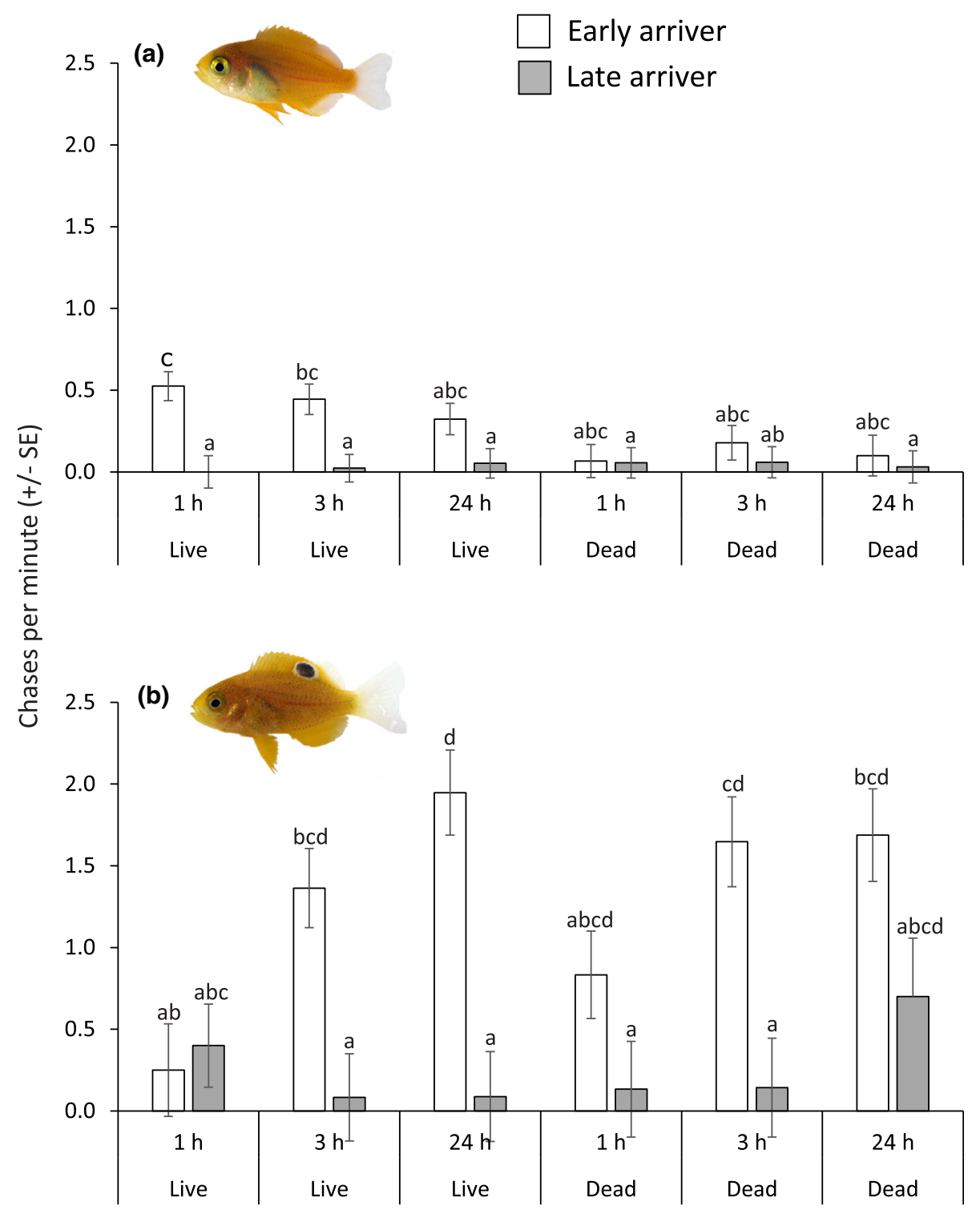

timing of arrival (1, 3 or $24 \mathrm{~h}$ ), the following interactions were staged on live coral and on dead coral (with different individuals): $P$. moluccensis arrived early (known as the 'resident') and $P$. amboinensis arrived late (known as the 'intruder'), or vice versa. Individuals on each patch were size-matched (mean difference in size $\pm \mathrm{SE}$ : $0.29 \pm 0.04 \mathrm{~mm}$; mean size $\pm \mathrm{SE}: 13.91 \pm 0.08 \mathrm{~mm} \mathrm{SL})$; fish were placed into a small zip-lock plastic bag of aerated seawater and measured for standard length using dial calipers. Fish were transported out to the study site in individually labelled plastic bags filled with aerated seawater within a 60L seawater-filled bin covered with shade cloth to reduce stress. All patches were vacant of any other fish that naturally recruited or migrated there. After the early arriver was placed on the patch reef $(\sim 10: 00 \mathrm{~h})$ and had been there for the appropriate time $(1,3$, or $24 \mathrm{~h})$, the late arriver was added and then both individuals were given a 30 min acclimation before behavioural observations were conducted. After a further $1 \mathrm{~min}$ acclimation period, a scuba diver (DEP) situated at least $1 \mathrm{~m}$ from the patch reef observed each fish sequentially (in random order with respect to treatment) for $3 \mathrm{~min}$, recording the following variables: the height of the fish on the patch reef (recorded as the percentage of time spent at the bottom, middle and top of the patch; found to be a useful measure of risk McCormick (2012)), and the number of chases towards the other individual (as per McCormick 2009; as a measure of aggression). Previous studies have found that behaviour of these species is sufficiently consistent to enable the characterisation of individual behaviour through a single three min observation period, demonstrating high levels of repeatability (McCormick 2009; White et al. 2015). 
口Early P. moluccensis $\square$ Early P. amboinensis

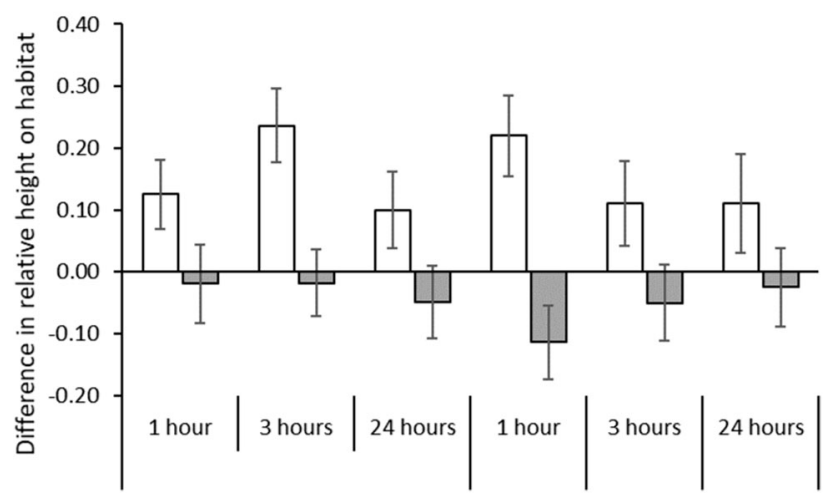

Fig. 2 Difference in relative height on the patch reef ( \pm SE) between early and late-arriving (i.e., resident and intruder) Pomacentrus moluccensis and P. amboinensis on live and dead coral, when timing of arrival for late individuals is 1,3 or $24 \mathrm{~h}$. White bars represent differences in height between early $P$. moluccensis and late $P$. amboinensis and grey bars represent differences in height between early $P$. amboinensis and late $P$. moluccensis. Differences are calculated from the perspective of the early-arriver, i.e., relative height of the early-arriver individual minus relative height of the latearriver. Therefore a positive value indicates the early-arriver was higher on the patch reef than the late-arriver, and vice versa. Numbers of replicates from left to right: $20,16,18,22,17,10,15,18,14,17$, 19,19

\section{Experiment 2: migration}

To assess propensity to migrate between habitats differing in their quality, sets of two patch reefs (one live coral and one dead coral) were set up $0.4 \mathrm{~m}$ apart and a non-transparent black plastic divider was placed between them to prevent a fish from seeing and moving to the adjacent patch (as per McCormick (2009)). In the first part of this study, the early arriver was placed on either the live or dead patch reef, followed by the late arriver $3 \mathrm{~h}$ later, to the same patch, according to the following four treatments: (1) $P$. amboinensis placed on the live coral patch reef followed by $P$. moluccensis $3 \mathrm{~h}$ later, (2) P. moluccensis placed on the live coral patch reef followed by $P$. amboinensis $3 \mathrm{~h}$ later, and (3) and (4) as per treatments one and two, except both fish placed on the dead coral patch reef rather than live. A 30 min acclimation period was given after the late arriver was added, and then the plastic divider was removed so that the adjacent patch reef could be seen by both fish. A further 30 min acclimation period was given before divers recorded the presence and location (i.e., dead or live coral) of each fish.

\section{Experiment 2: survival}

Using the same patch reef setup as above, we tested survival of a single species ( $P$. amboinensis, the generalist) in relation to migration, habitat quality, and sequence and timing of arrival. To test survival, one $P$. amboinensis individual was placed on the live coral patch reef and one on the dead coral simultaneously - these were the early arrivers. A $24 \mathrm{~h}$ priority was given to these fish before one more $P$. amboinensis individual was added to each of the live and dead coral patch reefs (the late arrivers). This simulated fish arriving on consecutive days within a recruitment pulse. Each of the four fish were tagged a different colour with a subcutaneous elastomer tag (as in (Hoey and McCormick 2004)) one day prior to transportation to patch reefs, in order to identify between individuals as well as to distinguish between our study fish and those that may have naturally recruited to the patch reefs. All individuals on the same patch reef were size-matched (as per the competition experiment; mean difference in size \pm SE: $0.58 \pm 0.05 \mathrm{~mm}$ ). Natural settlement was low during the study period and any new recruits were removed daily from patch reefs using a hand net. Migration and survival of each tagged individual were monitored daily at approx. 10:00 h for six days. Mortality was defined as not finding a fish on its allocated patch reef, or on any of the neighbouring patch reefs.

\section{Statistical analyses}

To compare the rate of chases towards competitors, general linear models (GLM) were undertaken for each species incorporating four factors: Status (Early arriver, Late arriver), Priority (timing of arrival: 1, 3, $24 \mathrm{~h}$ ) and Habitat type (Live, Dead). Type III sums of squares were used to account for unequal replication. Significant interactions were explored using Tukey's HSD for unequal sample sizes. 'Chases per minute' was $\log _{10}$ transformed to meet the assumptions of GLM, which were examined with residual analysis.

Difference in relative height on the patch reef was compared between Late-arriving species ( $P$. moluccensis or P. amboinensis), Habitat (Live, Dead) and Priority (timing of arrival: 1, 3, $24 \mathrm{~h}$ ) with GLM. Relative height on the patch was summarized as a cumulative proportion of the time spent at varying heights over the 3 min observation period, with the top of the patch taken as height of 1 , midpatch a height of 0.5 , and bottom a height of 0 (McCormick 2009). The difference in relative height between 'early' and 'late' arriving individuals was further calculated from the perspective of the early arriver, i.e., relative height of early individual minus relative height of late individual. Effect sizes are given as partial-eta-squared $\left(\eta_{p}{ }^{2}\right)$, which represents the proportion of the total variance in a dependent variable that is associated with the membership of different groups. The number of independent replicates for each of 3 prior residency periods by 2 early-arriving 
species by 2 habitats (i.e., 12 combinations) varied from 10 to 22 (mean 17).

Percentage migration from dead to live coral for early or late arriving $P$. amboinensis and $P$. moluccensis was compared using chi-square $\left(\chi^{2}\right)$ tests. Survival trajectories of $P$. amboinensis individuals arriving early or late to live or dead coral (and either remaining there or migrating from dead to live coral) were compared using the Kaplan-Meier product-limit method. Projected survival trajectories were compared across all six treatment combinations (grouped by the same habitat association, but difference in sequence of arrival) using a generalization of Gehan's generalized Wilcoxon test, Peto and Peto's generalized Wilcoxon test, and the log-rank test (Statistica version 13). Planned contrasts between particular treatment pairs were undertaken to explore the nature of the overall significance among treatments using a Cox's $F$-tests.

\section{Results}

\section{Experiment 1: competition}

The way in which habitat, timing of arrival and priority time influenced aggression (as measured by the number of chases) differed between species (Fig. 1a, b; Supplementary Table S1a, b). The number of chases undertaken by $P$. moluccensis was affected by their status (i.e., whether they were the early or late-arriver) and the habitat type they were on (Status $\times$ Habitat interaction, $F_{1,190}=9.50$, $p=0.002$ ). In live coral early-arrivers were more aggressive than late-arrivers, while this was not the case when on dead coral (Fig. 1a). In contrast, for P. amboinensis the story was more complex with aggression being affected by a significant three way interaction (Status $\mathrm{x}$ Habitat $\mathrm{x}$ Prior time, $\left.F_{2,190}=4.24, p=0.016\right)$. This was caused by $P$. amboinensis becoming more aggressive with residence time, and early-arrivers that had been on the patch for an hour tending to be more aggressive on dead coral than live (Fig. 1b). When the effect sizes $\left(\eta_{p}{ }^{2}\right)$ were examined, residence status played a more important role in influencing aggressive behaviour for $P$. amboinensis than $P$. moluccensis (Sup Table S1; 0.19 vs. 0.1).

The difference in relative height between the early and late arriver on the patch reef was affected only by which species was first $\left(F_{1,190}=29.26, p<0.001, \eta_{p}{ }^{2}=0.13\right.$; Fig. 2), and not by the priority period or habitat type $\left(F_{2,190}=0.31, \quad p=0.73\right.$ and $F_{1,190}=0.32, \quad p=0.57$, respectively; Fig. 2, Table $\mathrm{S} 2$ ). When $P$. moluccensis arrived early, they occupied higher areas on the patch reef than the late-arriving $P$. amboinensis (indicated by the positive values). Conversely, when $P$. amboinensis arrived early they continued to occupy lower areas of the habitat than late-arriving $P$. moluccensis (indicated by the negative values); however, the difference in height between species was reduced (Fig. 2). This trend is likely a result of heightened aggression by $P$. amboinensis when arriving early, leading the species to interact more frequently and thus leading to a decrease in height separation on the patch.

\section{Experiment 2: migration}

There was no migration from live to dead coral for either species and only one fish of any pair moved patches. Migration from dead to live coral occurred almost immediately (within $30 \mathrm{~min}$ of the dividers being lifted so they could see the alternative habitat), and was equal for early $P$. amboinensis and late-arriving $P$. moluccensis $(25 \%$ for both species; $\chi^{2}{ }_{1,32}<0.0001, p=1.000$; Fig. 3$)$. When $P$. moluccensis was the early and $P$. amboinensis the latearriver, migration from dead to live coral was significantly higher for $P$. moluccensis $\left(73 \%\right.$ compared to $0 \% ; \chi^{2}$ $1,30=17.368, p<0.001$; Fig. 3).

Migration from dead to live coral occurred significantly more frequently in $P$. amboinensis individuals when they arrived early (before P. moluccensis) compared to when they arrived late (after P. moluccensis) (25\% and $0 \%$, respectively; $\chi^{2}{ }_{1,31}=4.306, p=0.038$; Fig. 3 ). Similarly for $P$. moluccensis, migration from dead to live coral was also significantly higher when they arrived early compared to late $\left(73 \%\right.$ and $25 \%$, respectively; $\chi^{2}{ }_{1,31}=7.242$, $p=0.007)$; however, propensity to migrate was greater for P. moluccensis than for P. amboinensis (Fig. 3).

\section{Experiment 2: survival}

In a separate experiment using a single species $(P$. amboinensis), migration of individuals occurred from dead

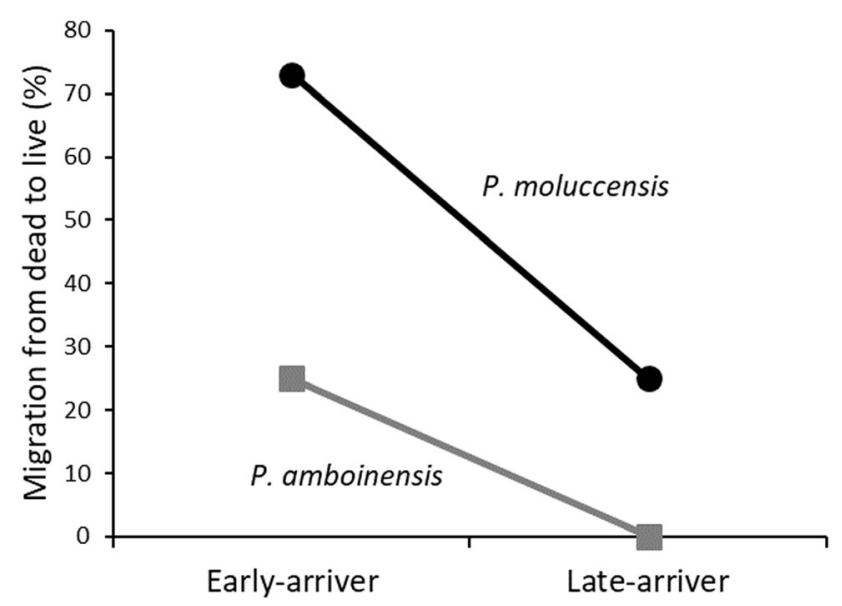

Fig. 3 Percentage migration from dead to live coral for Pomacentrus amboinensis (habitat generalist) and $P$. moluccensis (live coral specialist) arriving early or late. The prior residency period was $3 \mathrm{~h}$ 
to live coral, but not from live to dead coral. Individuals that migrated did so in less than one day and remained on that patch (i.e., did not return to the original patch) until they died or until the experiment was terminated (after six days).

Survival trajectories of newly-settled $P$. amboinensis were affected by habitat type and order of arrival overall $\left(\chi^{2}{ }_{5}=16.191, p=0.006\right.$, Fig. 4$)$, and the extent of these influences were further examined for specific treatment pairs. Mortality was not affected by prior residency for fish arriving at and migrating to the same habitat type [Earlyarrival to live coral ('Early-Live') vs late-arrival to live coral ('Late-Live'): Cox's $F$-test, $\quad F_{18,18}=1.343$, $p=0.269$; Early-arrival to dead coral ('Early-Dead') vs late-arrival to dead coral ('Late-Dead'): Cox's F-test, $F_{22,24}=1.706, p=0.102$; Early-arrival to dead coral then migrated to live coral ('Early-Dead-Live') vs late-arrival to dead then migrated to live coral ('Late-Dead-Live'): Cox's $F$-test, $F_{10,12}=1.430, p=0.312$, Fig. 4]. This suggests habitat types is the major driver of the overall significant difference in mortality trajectories among treatment combinations.

Mortality of fish on live coral was not affected by migration (i.e., mortality was similar between fish that arrived to live coral and fish that migrated from dead to live coral), regardless of whether they arrived early or late (Early-Live and Early-Dead-Live: Cox's $F$-test, $F_{22,10}=1.219, p=0.431$; Late-Live and Late-Dead-Live: Cox's $F$-test, $F_{20,10}=1.856, p=0.188$, Fig. 4). However, mortality of fish that arrived to dead coral was affected by migration and order of arrival; fish that stayed on dead coral experienced significantly higher mortality than fish that migrated from dead to live coral, but only if they arrived early (Early-Dead-Dead vs Early-Dead-Live: Cox's $F$-test, $F_{10,28}=2.456, \quad p=0.0439 ; \quad$ Late-Dead-Dead vs Late-Dead-Live: Cox's $F$-test, $F_{10,24}=1.789, p=0.134$, Fig. 4).

The survival of individuals who arrived simultaneously to different habitats and did not migrate was affected by habitat type, with individuals surviving better on live coral than dead coral (Early-Live and Early-Dead: $F_{18,24}=2.537, p=0.0171$; Fig. 4). Despite a lower survival rate for late-arrivers overall, the same trend was still evident, with late-arriving individuals to live coral doing better than late-arriving individuals to dead coral (LateLive and Late-Dead: $F_{18,22}=3.002, p=0.008$; Fig. 4). The fish that arrived late to dead coral and did not migrate were the only treatment in which all fish died prior to termination of the experiment (Fig. 4).

\section{Discussion}

Community dynamics are not only frequently altered by spatial and temporal variation in the arrival of new settlers and the emigration or mortality of residents (Shulman 1985; Dayton and Fitzgerald 2005; Booth and Beretta 2021), but also permanently impacted by environmental change (Herkert 1994; Tylianakis et al. 2008). The ways in which particular species respond to such change are a function of their life history characteristics, behaviour and versatility in the face of disruption (Gilchrist 1995; Caley
Fig. 4 Kaplan-Meier survival trajectories for Pomacentrus amboinensis arriving early or late (timing of arrival $=24 \mathrm{~h}$ ) to live or dead coral, with some individuals migrating from dead to live coral. (For example, 'Early-Live-Live' is an individual that arrived early to live coral and stayed on live; 'Early-Dead-Live' is an individual that arrived early to dead coral and migrated to live coral)

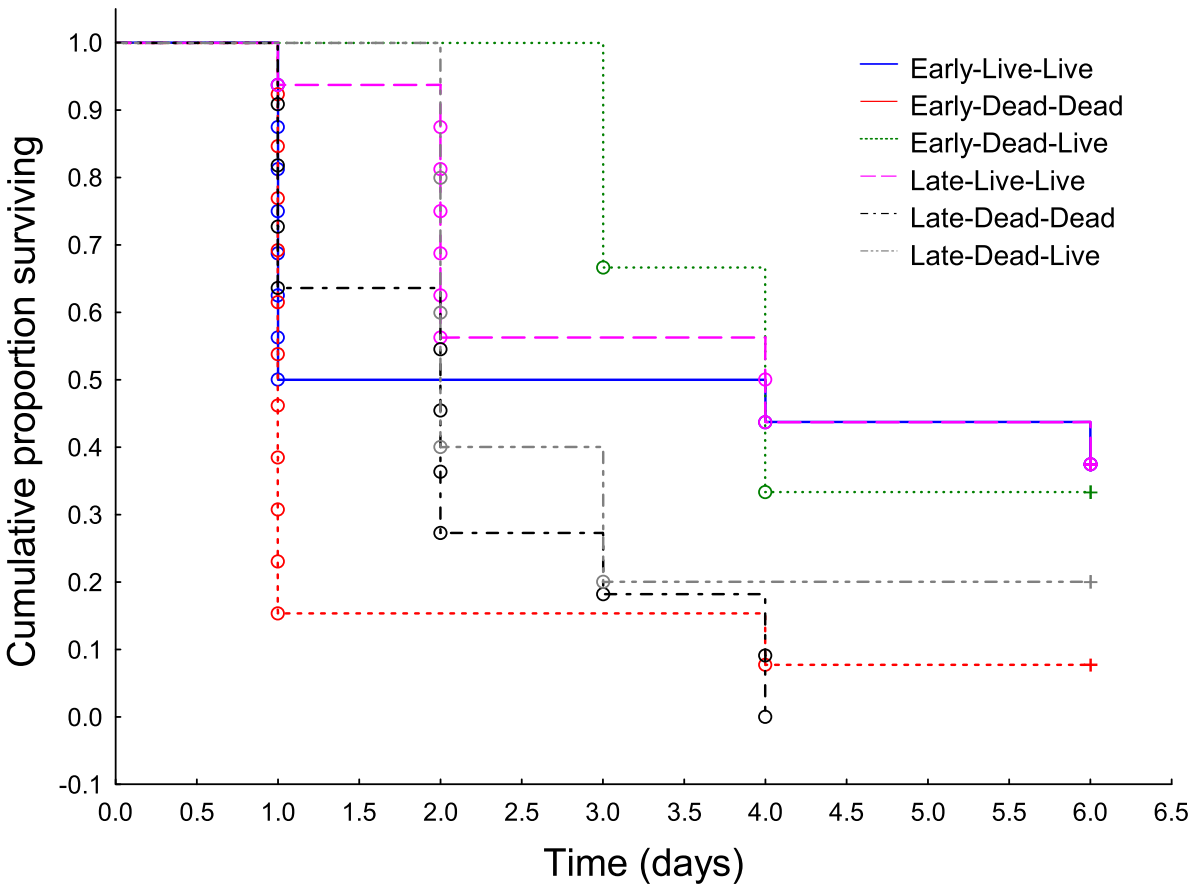


and Munday 2003; Devictor et al. 2008; McCormick et al. 2017). Understanding the complex nature of how these factors interact is essential for understanding how habitat degradation will affect communities of organisms. The present study demonstrates that priority effects modify how two species, which differ in their ecological versatility, perform in healthy and degrading habitats. The strength of priority effects intensified with increasing time since arrival, emphasising that resources become increasingly more valuable with lengthy prior residencies (also see (Geange and Stier 2009), but this only occurred for P. amboinensis (a habitat generalist). Early-arriving P. moluccensis (a specialist) defended its favourable habitat (live coral) only when given a $3 \mathrm{~h}$ priority, and conversely suffered increased aggression from $P$. amboinensis even when arriving early to dead coral habitats, suggesting that the priority advantage was overridden by the unfavourable (degraded) habitat type. Furthermore, after arriving $24 \mathrm{~h}$ late to dead coral, P. amboinensis displayed significantly more aggression towards $P$. moluccensis than was returned, indicating a low motivation or ability of this live coral specialist to compete in a degraded habitat, despite a significant prior residency advantage. These results are in keeping with the trade-off theory whereby specialists will display superior performance in preferred habitats, but inferior performance in other habitats (Berkström et al. 2014). Previous studies suggest that interspecific competition and habitat preference interact to influence post-settlement success (Bonin et al. 2009); however, the intensity of aggression (a result of sequence and timing of arrival) from direct competitors can further exacerbate these effects (Geange and Stier 2010).

Habitat use was affected by sequence of arrival, with the high level of aggression displayed by early $P$. amboinensis resulting in a reduced height separation between competitors on the patch reef, compared to when $P$. moluccensis arrived early. Previous studies have demonstrated similar resource partitioning between these species, where $P$. moluccensis generally occupies higher areas of the reef than P. amboinensis (McCormick 2012; McCormick and Weaver 2012); however, the present study suggests that increased aggression from the early-arriving $P$. amboinensis can disrupt this. This breakdown of resource partitioning has consequences for coexistence and the persistence of $P$. moluccensis, when arriving late. Although a variety of mechanisms exist by which species can coexist (Munday et al. 2001; Amarasekare 2002), previous studies have demonstrated the importance of interspecific competition in structuring communities (Bonin et al. 2015).

Propensity to migrate in search of higher quality habitat was affected by species identity as well as order of arrival. Early-arrivers were more likely to migrate from dead to live coral than late arrivers and $P$. moluccensis (a live coral specialist) was more likely to migrate to live coral than $P$. amboinensis, emphasising the value of live coral habitat to the specialist species. This is in contrast with the findings of Feary (2007) which showed specialist gobies to have a significantly lower propensity to migrate away from degrading habitat than generalist gobies, suggesting that the ability to survive in a partially degraded coral may have outweighed the potential increased predation risk of leaving. In the present study, arriving late reduced the propensity of $P$. moluccensis to migrate to live coral by almost 50\%, highlighting how sequence of arrival has significant implications for vulnerable juveniles by disrupting their ability or willingness to successfully seek higher quality (preferred) resources. This represents evidence of an inhibitory priority effect, whereby early-arriving $P$. amboinensis inhibits late-arriving $P$. moluccensis from migrating to adjacent favourable habitats. Additionally, $P$. amboinensis individuals that arrived to dead coral and did not migrate to live coral suffered higher mortality than those who did migrate, but this was only for earlyarriving individuals; late-arriving fish to dead coral and late-arriving fish that migrated to live coral experienced similarly high mortalities. This research emphasises the important role that high quality resources have on the persistence of organisms (Adam 2011; Kardol et al. 2013; Rudolf and McCrory 2018), even for those who are ecologically versatile; however, it also presents evidence of a priority effect whereby the disadvantage of arriving late overrides the advantage of migrating to live coral.

Evidence of an inhibitory priority effect in the migration component of the present study demonstrates the clear advantage of priority of access to valuable resources, particularly for $P$. moluccensis whose preferred live coral resource may be severely limited. Our results showed that willingness to seek out such resources was impeded by prior residents; however, the mechanisms by which this occurs are not clear. It is likely that $P$. moluccensis was competitively subordinate to $P$. amboinensis, particularly when it arrived late to dead coral, but also possibly when it arrived early to dead coral (as demonstrated by the competition experiment in our study). This suggests $P$. moluccensis may have been pushed out of the dead coral habitat by $P$. amboinensis (as we tend to see in competitive interactions between these and other species; Medeiros et al. 2010; McCormick and Weaver 2012)), if $P$. amboinensis chose to stay and not migrate, making the option to migrate a good alternative for $P$. moluccensis. Based on the direction of aggression in the competition experiment, aggression by $P$. amboinensis was likely stronger when $P$. moluccensis arrived late in the migration experiment, yet fewer $P$. moluccensis individuals chose to migrate when they arrived after $P$. amboinensis compared to when they arrived prior to $P$. amboinensis. Therefore, 
migration due to competitive subordinance does not appear to be the reason for choosing to migrate to preferred habitats, although it may still play a role. An alternative explanation for a larger proportion of $P$. moluccensis choosing to migrate from dead to live coral when they were prior residents (arriving $3 \mathrm{~h}$ before $P$. amboinensis), may be a result of their 3-h association with the dead coral habitat; a long enough period to fully explore the detrimental aspects of their new habitat. By contrast, when $P$. moluccensis arrived late, they were only subject to a 30 min acclimation before being able to migrate, and this shorter period may not have instilled the same level of dislike, resulting in fewer individuals migrating away from it. The competition experiment was suggestive of this with early-arriving $P$. moluccensis subject to significantly more aggression from $P$. amboinensis after inhabiting the dead coral habitat for $24 \mathrm{~h}$, compared to $1 \mathrm{~h}$ and $3 \mathrm{~h}$. It appears that the dead coral interferes with the ability of $P$. moluccensis to compete and even to locate more favourable habitat; however, this effect is further exacerbated by priority effects, severely disadvantaging late-arriving $P$. moluccensis. Coker et al. (Coker et al. 2012) suggests a willingness to remain on dead coral habitats is a result of aggressive dominance from individuals on neighbouring habitats, yet in the present study only $25 \%$ of $P$. amboinensis prior residents migrated, meaning a large proportion of neighbouring habitats were vacant of any competitors.

This study demonstrates both the negative and positive implications for a specialist in the face of resource degradation, whereby priority effects have the ability to either enhance or alleviate the effects of habitat degradation on this specialist species. Perhaps the most significant finding is that prior residency can mitigate the negative effects of habitat degradation on this habitat specialist and increase its propensity to migrate to higher quality habitats. Of course, this relies on live coral persisting under the currents threats to coral reefs; a dramatic decline would no doubt make specialist species highly susceptible to extinction simply as a result of their limited versatility (Munday 2004; Graham 2007; Wilson et al. 2008). The degree to which ecological versatility and priority effects modify competitive outcomes in coral reef fishes is important to understand, in order to predict how the changing environment will impact fish community dynamics. The present study was limited to incorporating only one specialist and one generalist species, so future research should examine a greater range of species with varying levels of resource specialisation, and across projected habitat degradation scenarios.
Supplementary Information The online version contains supplementary material available at https://doi.org/10.1007/s00338022-02229-8.

Acknowledgements Thank you to L. Pedini and S. Gardner for assistance with data collection, as well as staff at the Lizard Island Research Station (Australian Museum) for logistical support.

Funding Open Access funding enabled and organized by CAUL and its Member Institutions.

\section{Declarations}

Conflict of interest On behalf of all authors, the corresponding author states that there is no conflict of interest.

Ethical approval All research was conducted in accordance with the James Cook. University (JCU) Animal Ethics guidelines with approval from the JCU Animal Ethics Committee (approvals A1720 and A2080).

Data Accessibility Data are available on FigShare https://doi.org/10. 6084/m9.figshare. 12637379

Open Access This article is licensed under a Creative Commons Attribution 4.0 International License, which permits use, sharing, adaptation, distribution and reproduction in any medium or format, as long as you give appropriate credit to the original author(s) and the source, provide a link to the Creative Commons licence, and indicate if changes were made. The images or other third party material in this article are included in the article's Creative Commons licence, unless indicated otherwise in a credit line to the material. If material is not included in the article's Creative Commons licence and your intended use is not permitted by statutory regulation or exceeds the permitted use, you will need to obtain permission directly from the copyright holder. To view a copy of this licence, visit http://creativecommons. org/licenses/by/4.0/.

\section{References}

Adam TC (2011) High-quality habitat and facilitation ameliorate competitive effects of prior residents on new settlers. Oecologia 166:121-130

Amarasekare P (2002) Interference competition and species coexistence. Proc Roy Soc Lond B 269:2541-2550

Beaugrand JP, Payette D, Goulet C (1996) Conflict outcome in male green swordtail fish dyads (Xiphophorus herirrie): interaction of body size, prior dominance/subordination experience, and prior residency. Behaviour 133:303-319

Bergmüller R, Taborsky M (2010) Animal personality due to social niche specialisation. Trends Ecol Evol 25:504-511

Berkström C, Jones GP, McCormick MI (2014) Trade-offs in the ecological versatility of juvenile wrasses: an experimental evaluation. J Exp Mar Biol Ecol 453:91-97

Berkström C, Jones GP, McCormick MI, Srinivasan M (2012) Ecological versatility and consequences for the distribution and abundance of coral reef wrasses in Kimbe Bay, Papua New Guinea. Mar Ecol Prog Ser 461:151-163

Bonin MC, Boström-Einarsson L, Munday PL, Jones GP (2015) The prevalence and importance of competition among coral reef fishes. Annu Rev Ecol Evol Syst 46:169-190

Bonin MC, Munday PL, McCormick MI, Srinivasan M, Jones GP (2009) Recruitment and persistence of coral-dwelling fishes is 
resilient to bleaching but not mortality of host corals. Mar Ecol Prog Ser 394:215-222

Booth BJ, Kingsford MJ, Doherty PJ, Beretta GA (2000) Recruitment of damselfishes in One Tree Island lagoon: persistent interannual spatial patterns. Mar Ecol Prog Ser 202:219-230

Booth DJ, Beretta GA (2021) Long-term demographics of a coral-reef fish: growth, survival and abundance at several spatial scales. Coral Reefs 40:1257-1266

Caley MJ, Munday PL (2003) Growth trades off with habitat specialization. Proc R Soc Lond B 270:S175-S177

Ceballos G, Ehrlich PR, Dirzo R (2017) Biological annihilation via the ongoing sixth mass extinction signaled by vertebrate population losses and declines. Proc Natl Acad Sci 114:E6089-E6096

Cheal AJ, MacNeil MA, Emslie MJ, Sweatman H (2017) The threat to coral reefs from more intense cyclones under climate change. Global Change Biol 23:1511-1524

Clavel J, Julliard R, Devictor V (2011) Worldwide decline of specialist species: toward a global functional homogenization? Front Ecol Environ 9:222-228

Coker D, Wilson S, Pratchett M (2014) Importance of live coral habitat for reef fishes. Rev Fish Biol Fish 24:89-126

Coker DJ, Pratchett MS, Munday PL (2012) Influence of coral bleaching, coral mortality and conspecific aggression on movement and distribution of coral-dwelling fish. J Exp Mar Biol Ecol 414:62-68

Colles A, Liow LH, Prinzing A (2009) Are specialists at risk under environmental change? Neoecological, paleoecological and phylogenetic approaches. Ecol Lett 12:849-863

Dayton G, Fitzgerald L (2005) Priority effects and desert anuran communities. Can J Zool 83:1112-1116

De'ath G, Fabricius KE, Sweatman H, Puotinen M (2012) The 27-year decline of coral cover on the Great Barrier Reef and its causes. PNAS 109:17995-17999

Devictor V, Julliard R, Jiguet F (2008) Distribution of specialist and generalist species along spatial gradients of habitat disturbance and fragmentation. Oikos 117:507-514

Dixon PA, Milicich MJ, Sugihara G (1999) Episodic fluctuations in larval supply. Science 283:1528-1530

Dufour V, Galzin R (1993) Colonization patterns of reef fish larvae to the lagoon at Moorea Island, French Polynesia. Mar Ecol Prog Ser 102:143-152

Evans DL, Shehadi-Moacdieh M (1988) Body size and prior residency in staged encounters between female prawns, Palaemon elegans Rathke (Decapoda: Palaemonidae). Anim Behav $36: 452-455$

Fabricius KE (2005) Effects of terrestrial runoff on the ecology of corals and coral reefs: review and synthesis. Mar Pollut Bull 50:125-146

Feary DA (2007) The influence of resource specialization on the response of reef fish to coral disturbance. Mar Biol 153:153-161

Feary DA, Pratchett MS, Emslie MJ, Fowler AM, Figueira WF, Luiz OJ, Nakamura Y, Booth DJ (2014) Latitudinal shifts in coral reef fishes: why some species do and others do not shift. Fish Fish 15:593-615

Ferrari MCO, McCormick MI, Meekan MG, Chivers DP (2015) Background level of risk and the survival of predator-naïve prey: can neophobia compensate for predator naivety in juvenile coral reef fishes? Proc R Soc Lond B 282:20142197

Gagliano M, McCormick MI (2007) Compensating in the wild: is flexible growth the key to early juvenile survival? Oikos 116:111-120

Gagliano M, McCormick MI, Meekan MG (2007) Survival against the odds: ontogenetic changes in selective pressure mediate growth-mortality tradeoffs in a marine fish. Proc R Soc Lond B 274:1575-1582
Geange SW, Stier AC (2009) Order of arrival affects competition in two reef fishes. Ecology 90:2868-2878

Geange SW, Stier AC (2010) Priority effects and habitat complexity affect the strength of competition. Oecologia 163:111-118

Gilchrist GW (1995) Specialists and generalists in changing environments. I. Fitness landscapes of thermal sensitivity. Am Nat 146:252-270

Gladstone-Gallagher RV, Pilditch CA, Stephenson F, Thrush SF (2019) Linking traits across ecological scales determines functional resilience. Trends Ecol Evol 34:1080-1091

Goldstein ED, Sponaugle S (2020) Juvenile reef fish growth and survival related to subregional patterns of primary production. Mar Biol 167:1-10

Graham NAJ (2007) Ecological versatility and the decline of coral feeding fishes following climate driven coral mortality. Mar Biol 153:119-127

Herkert JR (1994) The effects of habitat fragmentation on midwestern grassland bird communities. Ecol Appl 4:461-471

Hodge S, Arthur W, Mitchell P (1996) Effects of temporal priority on interspecific interactions and community development. Oikos 76:350-358

Hoey AS, McCormick MI (2004) Effects of subcutaneous fluorescent tags on the growth and survival of a newly settled coral reef fish, Pomacentrus amboinensis (Pomacentridae). In: 10th International Coral Reef Symposium, pp 420-424

Huey RB, Kearney MR, Krockenberger A, Holtum JAM, Jess M, Williams SE (2012) Predicting organismal vulnerability to climate warming: roles of behaviour, physiology and adaptation. Philos Trans R Soc B-Biol Sci 367:1665-1679

Hughes TP, Barnes ML, Bellwood DR, Cinner JE, Cumming GS, Jackson JBC, Kleypas J, van de Leemput IA, Lough JM, Morrison TH, Palumbi SR, van Nes EH, Scheffer M (2017) Coral reefs in the Anthropocene. Nature 546:82-90

Jones GP, McCormick MI, Srinivasan M, Eagle JV (2004) Coral decline threatens fish biodiversity in marine reserves. PNAS 101:8251-8253

Kardol P, Souza L, Classen AT (2013) Resource availability mediates the importance of priority effects in plant community assembly and ecosystem function. Oikos 122:84-94

Kleypas J, Allemand D, Anthony K, Baker AC, Beck MW, Hale LZ, Hilmi N, Hoegh-Guldberg O, Hughes T, Kaufman L, Kayanne H, Magnan AK, McLeod E, Mumby P, Palumbi S, Richmond RH, Rinkevich B, Steneck RS, Voolstra CR, Wachenfeld D, Gattuso J-P (2021) Designing a blueprint for coral reef survival. Biol Conserv 257:109107

Lawler SP, Morin PJ (1993) Temporal overlap, competition, and priority effects in larval anurans. Ecology 74:174-182

Leis JM, McCormick MI (2002) The biology, behavior, and ecology of the pelagic, larval stage of coral reef fishes. In: Sale PF (ed) Coral reef fishes - dynamics and diversity in a complex ecosystem. Academic Press, London, pp 171-199

Lewis AR (1997) Recruitment and post-recruitment immigration affect the local population size of coral reef fishes. Coral Reefs 16:139-149

MacNally RC (1995) Ecological versatility and community ecology. Cambridge University Press

Madin JS, Hoogenboom MO, Connolly SR, Darling ES, Falster DS, Huang DW, Keith SA, Mizerek T, Pandolfi JM, Putnam HM, Baird AH (2016) A trait-based approach to advance coral reef science. Trends Ecol Evol 31:419-428

McCormick MI (2009) Behaviourally mediated phenotypic selection in a disturbed coral reef environment. PLoS ONE 4:e7096

McCormick MI (2012) Lethal effects of habitat degradation on fishes through changing competitive advantage. Proc Roy Soc Lond B 279:3899-3904 
McCormick MI, Makey LJ (1997) Post-settlement transition in coral reef fishes: overlooked complexity in niche shifts. Mar Ecol Prog Ser 153:247-257

McCormick MI, Weaver CJ (2012) It pays to be pushy: intracohort interference competition between two reef fishes. PLoS ONE $7: \mathrm{e} 42590$

McCormick MI, Lönnstedt OM (2016) Disrupted learning: habitat degradation impairs crucial antipredator responses in naïve prey. Proc R Soc Lond B 283:20160441

McCormick MI, Moore JAY, Munday PL (2010a) Influence of habitat degradation on fish replenishment. Coral Reefs 29:537-546

McCormick MI, Barry R, Allan BJM (2017) Algae associated with coral degradation affects risk assessment in coral reef fishes. Sci Rep 7:16937

McCormick MI, Ryen CA, Munday PL, Walker SPW (2010b) Differing mechanisms underlie sexual size-dimorphism in two populations of a sex-changing fish. PLoS ONE 5:e10616

McKenzie DJ, Axelsson M, Chabot D, Claireaux G, Cooke SJ, Corner RA, De Boeck G, Domenici P, Guerreiro PM, Hamer B, Jorgensen C, Killen SS, Lefevre S, Marras S, Michaelidis B, Nilsson GE, Peck MA, Perez-Ruzafa A, Rijnsdorp AD, Shiels HA, Steffensen JF, Svendsen JC, Svendsen MBS, Teal LR, van der Meer J, Wang T, Wilson JM, Wilson RW, Metcalfe JD (2016) Conservation physiology of marine fishes: state of the art and prospects for policy. Conserv Physiol 4

Medeiros P, Souza A, Ilarri M (2010) Habitat use and behavioural ecology of the juveniles of two sympatric damselfishes (Actinopterygii: Pomacentridae) in the south-western Atlantic Ocean. J Fish Biol 77:1599-1615

Meekan MG, Wilson SG, Halford A, Retzel A (2001) A comparison of catches of fishes and invertebrates by two light trap designs, in tropical NW Australia. Mar Biol 139:373-381

Morris DW (1996) Coexistence of specialist and generalist rodents via habitat selection. Ecology 77:2352-2364

Munday PL (2004) Habitat loss, resource specialization, and extinction on coral reefs. Glob Change Biol 10:1642-1647

Munday PL, Jones GP, Caley MJ (2001) Interspecific competition and coexistence in a guild of coral-dwelling fishes. Ecology 82:2177-2189

Öhman MC, Munday PL, Jones GP, Caley MJ (1998) Settlement strategies and distribution patterns of coral-reef fishes. J Exp Mar Biol Ecol 225:219-238

Pihl L, Baden S, Kautsky N, Rönnbäck P, Söderqvist T, Troell M, Wennhage H (2006) Shift in fish assemblage structure due to loss of seagrass Zostera marina habitats in Sweden. Estuar Coast Shelf Sci 67:123-132

Poulos DE, McCormick MI (2014) Who wins in the battle for space? The importance of priority, behavioural history and size. Anim Behav 90:305-314

Pratchett MS, Coker DJ, Jones GP, Munday PL (2012) Specialization in habitat use by coral reef damselfishes and their susceptibility to habitat loss. Ecol Evol 2:2168-2180
Rollins HB, Benard MF (2020) Challenges in predicting the outcome of competition based on climate change-induced phenological and body size shifts. Oecologia 193:749-759

Rudolf VHW, McCrory S (2018) Resource limitation alters effects of phenological shifts on inter-specific competition. Oecologia 188:515-523

Sanchez-Bayo F, Wyckhuys KAG (2019) Worldwide decline of the entomofauna: A review of its drivers. Biol Conserv 232:8-27

Schmitt RJ, Holbrook SJ (1999) Mortality of juvenile damselfish: Implications for assessing processes that determine abundance. Ecology 80:35-50

Shulman MJ (1985) Recruitment of coral reef fishes: effects of distribution of predators and shelter. Ecology 66:1056-1066

Smale DA, Wernberg T, Oliver ECJ, Thomsen M, Harvey BP, Straub SC, Burrows MT, Alexander LV, Benthuysen JA, Donat MG, Feng M, Hobday AJ, Holbrook NJ, Perkins-Kirkpatrick SE, Scannell HA, Sen Gupta A, Payne BL, Moore PJ (2019) Marine heatwaves threaten global biodiversity and the provision of ecosystem services. Nat Clim Change 9:306

Stuart-Smith RD, Brown CJ, Ceccarelli DM, Edgar GJ (2018) Ecosystem restructuring along the Great Barrier Reef following mass coral bleaching. Nature 560:92

Sweatman H (1988) Field evidence that settling coral reef fish larvae detect resident fishes using dissolved chemical cues. J Exp Mar Biol Ecol 124:163-174

Sweatman HPA (1985) The influence of adults of some coral reef fishes on larval recruitment. Ecol Monog 55:469-485

Symons CC, Arnott SE (2014) Timing is everything: priority effects alter community invasibility after disturbance. Ecol Evol 4:397-407

Tucker CM, Fukami T (2014) Environmental variability counteracts priority effects to facilitate species coexistence: evidence from nectar microbes. Proc R Soc Lond B 281:20132637

Tylianakis JM, Didham RK, Bascompte J, Wardle DA (2008) Global change and species interactions in terrestrial ecosystems. Ecol Lett 11:1351-1363

Vail A, McCormick MI (2011) Metamorphosing reef fishes avoid predator scent when choosing a home. Biol Lett 7:921-924

White JR, Meekan MG, McCormick MI (2015) Individual consistency in the behaviors of newly-settled reef fish. PeerJ 3:e961

Williams DM, English S, Milicich MJ (1994) Annual recruitment surveys of coral reef fishes are good indicators of patterns of settlement. Bull Mar Sci 54:314-331

Wilson SK, Burgess SC, Cheal AJ, Emslie MJ, Fisher R, Miller I, Polunin NVC, Sweatman HPA (2008) Habitat utilization by coral reef fish: implications for specialists vs. generalists in a changing environment. J Anim Ecol 77:220-228

Publisher's Note Springer Nature remains neutral with regard to jurisdictional claims in published maps and institutional affiliations. 